\title{
Surgical treatment of multivalvular endocarditis: Twenty-one-year single center experience
}

Feng Yao, MD, Lin Han, MD, Zhi-yun Xu, MD, Liang-jian Zou, MD, Sheng-dong Huang, MD, Zhi-nong Wang, MD, Fang-lin Lu, MD, and Ying-long Yao, MD

Objective: Little information is available about surgical outcomes in patients with multivalvular endocarditis. The aim of this article is to review the 21-year experience with surgical treatment of patients with multivalvular endocarditis at our institution and, in particular, to determine the incidence, pathologic status, diagnosis, surgical strategies, and outcomes of patients with this disease.

Methods: From January 1986 to December 2006, a total of 48 patients ( 40 men, 8 women), with a mean age of 42 \pm 12 years, underwent surgery for multivalvular endocarditis. Endocarditis was active in 32 patients and healed in 16. Preoperative transthoracic echocardiographic evaluation was performed in all 48 patients with addition of transesophageal echocardiography in $22(45.8 \%)$. Intraoperative findings showed that the endocarditis involved mostly the mitral and aortic valves (40/48 patients). Triple or quadruple valve involvement was found in 1 and 2 patients, respectively. Preoperative, perioperative, and postoperative data were retrospectively analyzed and risk factors for early and late survival were determined.

Results: In only $24(50.0 \%)$ patients was multivalvular endocarditis diagnosed by preoperative transthoracic echocardiography; 17 (77.3\%) patients had multivalvular endocarditis confirmed by preoperative transesophageal echocardiography. The 30-day hospital mortality was $12.5 \%(\mathrm{n}=6)$. Preoperative renal failure, New York Heart Association class IV, and emergency surgery were identified as independent risk factors for hospital mortality. Overall long-term survival was $74 \% \pm 6 \%$ at 5 years and $62 \% \pm 3 \%$ at 10 years. Multivariate analysis revealed that renal failure and recurrent endocarditis were associated with increased late mortality. Ten-year freedom from recurrent endocarditis was $74 \% \pm 5 \%$ and 10 -year freedom from reoperation was $73 \% \pm 6 \%$.

Conclusions: In our institution, multivalvular endocarditis was diagnosed by transthoracic echocardiography in only half of the patients. Intraoperative transesophageal echocardiography provided a more effective means to identify this disease. Radical resection of all infected tissues for patients with multivalvular endocarditis and additional intraoperative interventions, depending on the intraoperative pathologic condition, produced satisfactory in-hospital and long-term results, similar to those in patients with a single infected heart valve.

Even though great improvements have been made in general health care and antibiotic therapy, the incidence of infective endocarditis has not changed during the past decades. ${ }^{1}$ Despite dramatic improvements in the natural history of infective endocarditis after the introduction of antimicrobial therapy, ${ }^{2}$ this entity remains a serious disease that requires surgical intervention in up to $20 \%$ to $40 \%$ of affected patients. ${ }^{3,4}$ Surgical treatment of native valve endocarditis (NVE) involving a single valve is well documented, with excellent results reported with both valve repair and replacement. ${ }^{5}$ However, little information is available concerning patients with multivalvular endocarditis (MVE) that affects simultaneously at least two cardiac valves. Current under-

\footnotetext{
From the Department of Cardiothoracic Surgery, Changhai Hospital, Second Military Medical University, Shanghai, People's Republic of China.

F. Yao and L. Han contributed equally to this work.

Received for publication Aug 1, 2008; revisions received Oct 20, 2008; accepted for publication Nov 26, 2008

Address for reprints: Zhi-yun Xu, MD, Department of Cardiothoracic Surgery, Changhai Hospital, 174 Changhai Road, Shanghai 200433, People's Republic of China (E-mail: zhiyunx@hotmail.com).

J Thorac Cardiovasc Surg 2009;137:1475-80

$0022-5223 / \$ 36.00$

Copyright (c) 2009 by The American Association for Thoracic Surgery

doi:10.1016/j.jtcvs.2008.11.046
}

standing of MVE is primarily based on sporadic case reports $^{6-9}$ and not on systematic retrospective investigation. The purpose of this study was to review the 21-year experience with surgical treatment of patients with MVE at our institution and, in particular, to determine the incidence, pathologic status, diagnosis, surgical strategies, and shortterm and long-term surgical results of patients with MVE.

\section{PATIENTS AND METHODS}

A review of the cardiac surgery database of Shanghai Changhai Hospital (a 1000-bed tertiary care teaching hospital in southeast China with approximately 1200 cardiac operations performed in 2006) disclosed 388 patients who had surgery for NVE from January 1986 to December 2006. A total of 48 patients ( 40 men, 8 women), with a mean age of 42 \pm 12 years, underwent surgery for MVE. The review of these patients was approved by our institutional committee for human research. In patients with preoperative echocardiograms, the diagnosis of MVE was made using the Duke criteria. ${ }^{10}$ Endocarditis was considered to be active if the patient had positive blood cultures, operative findings of acute inflammation, or positive cultures or Gram stain of excised tissue. Endocarditis was considered to be healed if the operation occurred more than 6 weeks after the initial diagnosis, a course of antibiotics was completed, blood cultures were negative at the time of the operation, and cultures and Gram stains of intraoperatively excised tissue were negative. Characteristics of the patients are detailed in Table 1. Endocarditis was active in 32 patients and healed in 16 patients. Probable sources of infection were 


\author{
Abbreviations and Acronyms \\ $\mathrm{CHD}=$ congenital heart disease \\ $\mathrm{CI}=$ confidence interval \\ $\mathrm{MVE}=$ multivalvular endocarditis \\ $\mathrm{NVE}=$ native valve endocarditis \\ $\mathrm{OR}=$ odds ratio \\ TEE $=$ transesophageal echocardiography \\ TTE $=$ transthoracic echocardiography
}

identified in 11 patients, with 5 infections attributed to dental sources. Predisposing factors were found in 31 patients, with rheumatic heart valve disease in 18 , degenerative heart valve disease in 6 , and congenital heart disease (CHD) in 17. Information regarding the offending microorganism was available in 31 patients and is shown in Table 2. Streptococcus viridans was the most common microorganism, which occurred in $29.1 \%$ of the patients, followed by Staphylococcus infection (18.7\%) and Enterococcus infection (4.2\%). Preoperative transthoracic echocardiographic (TTE) evaluation was performed in all patients and transesophageal echocardiography (TEE) was also performed in 22 patients $(45.8 \%$, Table 3$)$. Coronary angiography was performed in most patients older than 50 years and in those with suspected coronary artery disease except if they had large vegetations near the coronary artery orifices.

\section{Operative Technique}

The primary indication for operation was congestive heart failure in $75 \%$ of patients. Other manifestations of endocarditis included persistent sepsis $(22.9 \%)$ and systemic emboli $(27.1 \%)$. Operation was performed electively in $47.9 \%$ and urgently or as an emergency in $52.1 \%$ (Table 1). All operations were carried out through a median sternotomy incision with moderate hypothermia during cardiopulmonary bypass. Myocardial protection was provided by the infusion of cardioplegic solution and topical cooling. Radical resection of all infected valvular and paravalvular tissues was the basic operative principle used in all patients. If the infection was limited to the leaflets of the valve, simple valve repair or replacement was performed. If the infection extended to the annulus or surrounding structures, a radical resection of the abscess and patch reconstruction of the annulus and adjoining structures was accomplished with either fresh autologous pericardium or glutaraldehyde-fixed bovine pericardium. Six attending surgeons performed the 48 operations. Table 4 summarizes the operative information. In $20 \%$ of patients with mitral and aortic valve involvement, mitral valve repair was performed, as has become increasingly common in recent years. A variety of mitral repair techniques were used, with pericardial patch repair of the anterior mitral leaflet being the most commonly applied technique. In recent years, allografts were implanted in the aortic position, and they have become the prosthesis of choice for the management of the aortic valve infection. For tricuspid or pulmonary valve endocarditis, our surgical principle is to repair the valve whenever possible or use a biological substitute without any artificial material that might become infected if valve replacement is inevitable.

\section{Follow-up}

Patients who had combined aortic valve replacement with mitral valve repair and those who had a triple or quadruple valve operation were followed up prospectively at annual intervals. The remaining patients were followed up irregularly up to 2006, but all patients were contacted in the first 5 months of 2007. Follow-up was completed by telephone contact with the patient, by analysis of standardized questionnaires that were mailed to the patients, by analyzing the population registry, or by contacting peripheral hospitals. The follow-up for this report was closed on June 1, 2007, and
TABLE 1. Patient characteristics

\begin{tabular}{|c|c|c|c|}
\hline Characteristics & $\begin{array}{c}\text { Total } \\
(n=48)\end{array}$ & $\begin{array}{l}\text { Active MVE } \\
(\mathbf{n}=\mathbf{3 2})\end{array}$ & $\begin{array}{l}\text { Healed MVE } \\
\quad(\mathbf{n}=16)\end{array}$ \\
\hline Mean age $\pm S D, y$ & $42 \pm 12$ & $48 \pm 13$ & $37 \pm 14$ \\
\hline Male gender & 40 & 29 & 11 \\
\hline \multicolumn{4}{|l|}{ No. of patients } \\
\hline $1980 \mathrm{~s}$ & 2 & 2 & 0 \\
\hline $1990 \mathrm{~s}$ & 21 & 12 & 9 \\
\hline $2000 \mathrm{~s}$ & 25 & 18 & 7 \\
\hline \multicolumn{4}{|l|}{ Predisposing factors } \\
\hline $\begin{array}{c}\text { Rheumatic heart } \\
\text { valve disease }\end{array}$ & 18 & 11 & 7 \\
\hline $\begin{array}{l}\text { Degenerated heart } \\
\text { valve disease }\end{array}$ & 6 & 4 & 2 \\
\hline $\begin{array}{l}\text { Congenital heart } \\
\text { disease: }\end{array}$ & 17 & 14 & 3 \\
\hline VSD & 5 & 4 & 1 \\
\hline $\begin{array}{l}\text { VSD and Valsalva } \\
\text { aneurysm }\end{array}$ & 2 & 1 & 1 \\
\hline ASD & 1 & 1 & 0 \\
\hline PDA & 2 & 2 & 0 \\
\hline $\mathrm{DCRV}+\mathrm{PS}$ & 1 & 1 & 0 \\
\hline TOF & 1 & 0 & 1 \\
\hline $\begin{array}{l}\text { Bicuspid aortic } \\
\text { valve disease }\end{array}$ & 5 & 5 & 0 \\
\hline \multicolumn{4}{|l|}{ Sites of infection } \\
\hline $\mathrm{MV}$ and $\mathrm{AV}$ & 40 & 27 & 13 \\
\hline $\mathrm{AV}$ and $\mathrm{TV}$ & 1 & 0 & 1 \\
\hline $\mathrm{AV}$ and $\mathrm{PV}$ & 2 & 0 & 2 \\
\hline $\mathrm{PV}$ and TV & 2 & 2 & 0 \\
\hline $\mathrm{MV}, \mathrm{AV}$, and $\mathrm{PV}$ & 1 & 1 & 0 \\
\hline $\mathrm{MV}, \mathrm{AV}, \mathrm{PV}$, and TV & 2 & 2 & 0 \\
\hline \multicolumn{4}{|l|}{ NYHA functional class } \\
\hline II & 7 & 2 & 5 \\
\hline III & 19 & 15 & 4 \\
\hline IV & 22 & 15 & 7 \\
\hline \multicolumn{4}{|l|}{ Electrocardiogram } \\
\hline Sinus rhythm & 32 & 21 & 11 \\
\hline Atrial fibrillation & 15 & 10 & 5 \\
\hline Complete heart block & 1 & 1 & 0 \\
\hline \multicolumn{4}{|l|}{ Associated diseases } \\
\hline Diabetes mellitus & 4 & 3 & 1 \\
\hline Hypertension & 6 & 5 & 1 \\
\hline $\begin{array}{l}\text { Chronic obstructive } \\
\text { lung disease }\end{array}$ & 2 & 1 & 1 \\
\hline $\begin{array}{l}\text { Renal insufficiency } \\
\qquad(\mathrm{Cr} \geq 2.0 \mathrm{mg} / \mathrm{dL})\end{array}$ & 8 & 7 & 1 \\
\hline Recent TIA/stroke & 8 & 6 & 2 \\
\hline Cardiogenic/septic shock & 2 & 2 & 0 \\
\hline Coronary artery disease & 2 & 1 & 1 \\
\hline $\begin{array}{l}\text { Left ventricular } \\
\quad \text { ejection fraction }<40 \%\end{array}$ & 5 & 2 & 3 \\
\hline \multicolumn{4}{|l|}{ Timing of operation } \\
\hline Same hospitalization & 23 & 10 & 13 \\
\hline Urgent/emergency & 25 & 22 & 3 \\
\hline
\end{tabular}


TABLE 1. Continued

\begin{tabular}{|c|c|c|c|}
\hline Characteristics & $\begin{array}{c}\text { Total } \\
(n=48)\end{array}$ & $\begin{array}{l}\text { Active MVE } \\
(\mathbf{n}=\mathbf{3 2})\end{array}$ & $\begin{array}{l}\text { Healed MVE } \\
\quad(n=16)\end{array}$ \\
\hline \multicolumn{4}{|l|}{ Surgical indications } \\
\hline Congestive heart failure & 36 & 27 & 9 \\
\hline Sepsis & 11 & 11 & 0 \\
\hline Emboli & 13 & 9 & 4 \\
\hline \multicolumn{4}{|c|}{$\begin{array}{l}M V E \text {, Multivalvular endocarditis; } S D \text {, standard deviation; } V S D \text {, ventricular septal de- } \\
\text { fect; } A S D \text {, atrial septal defect; } P D A \text {, patent ductus arteriosus; } D C R V+P S \text {, double- } \\
\text { chambered right ventricle and pulmonary valve stenosis; } T O F \text {, tetralogy of Fallot; } \\
M V \text {, mitral valve; } A V \text {, aortic valve; } T V \text {, tricuspid valve; } P V \text {, pulmonary valve; } \\
N Y H A \text {, New York Heart Association; } C r \text {, serum creatinine; } T I A \text {, transient ischemic } \\
\text { attack. }\end{array}$} \\
\hline
\end{tabular}

was $100 \%$ complete. The follow-up duration ranged from 7 months to 20 years (mean, 6.7 years), and the total cumulative follow-up was 348.4 patient-years. In $64.6 \%$ of patients, follow-up exceeded 5 years, and in $22.9 \%$ it exceeded 10 years.

\section{Statistical Analysis}

Descriptive statistics are reported as mean \pm standard deviation for continuous variables and as frequencies and percentages for categorical variables. Risk factors for early mortality analysis were performed by the $\chi^{2}$ test, Fisher's exact test, and a multivariate logistic regression model. Long-term survival or freedom from morbid events was evaluated by univariate analysis with the log-rank test, and the stepwise Cox proportional hazards approach was used to develop a multivariable model. The variables with $P<.1$ on univariate analysis were entered into a multivariable analysis. Survival curves were described by the Kaplan-Meier method. Statistical analyses were performed on a personal computer using SAS 8.1 software for Windows (SAS Institute, Cary, NC).

\section{RESULTS}

In our patient population, endocarditis affecting multiple valves accounted for $12.4 \%$ of all patients with endocarditis operated on at our institution. MVE was confirmed in all patients with intraoperative findings and pathologic examination, whereas only $24(50.0 \%)$ cases of MVE were diagnosed by preoperative TTE and $17(35.4 \%)$ additional cases were confirmed by preoperative TEE (Table 3 ).

We are following the recommendations of the most recent guidelines to report mortality and morbidity. ${ }^{11}$ There were 6 $(12.5 \%)$ operative deaths. The causes of death were often multifactorial, but the main reasons were septic shock in 1 patient, low cardiac output syndrome in 1 patient, renal failure in 2 patients, multiorgan failure in 1 patient, and cerebral

TABLE 2. Offending microorganisms

\begin{tabular}{lc}
\hline \multicolumn{1}{c}{ Microorganisms } & No. of patients \\
\hline Streptococcus viridans & $14(29.1)$ \\
Other streptococci & $2(4.2)$ \\
Staphylococcus aureus & $7(14.5)$ \\
Staphylococcus epidermidis & $2(4.2)$ \\
Enterococcus faecalis & $2(4.2)$ \\
Other bacteria & $4(8.4)$ \\
Culture-negative endocarditis & $17(35.4)$ \\
\hline
\end{tabular}

Percentages are shown in parentheses. embolism in 1 patient. Logistic regression analysis identified preoperative renal failure (odds ratio [OR] 5.9, 95\% confidence interval [CI] 3.3-8.6), New York Heart Association class IV (OR 2.7, 95\% CI 1.3-4.0), and emergency surgery (OR 2.5, 95\% CI 1.2-4.4) as predictors of operative death.

Postoperative complications were common: 4 patients had respiratory insufficiency, 2 patients required re-exploration for bleeding and/or tamponade, 1 patient required insertion of a permanent pacemaker for heart block, and 2 required hemodialysis for new postoperative renal failure.

Twelve patients died during the follow-up period. The causes of late deaths were cardiac related in 4 (congestive heart failure in 3 and myocardial infarction in 1), valve related in 6 ( 1 caused by structural valve deterioration and 5 caused by recurrent endocarditis), and other causes in 2 (cancer in 1 and diabetes in 1). Overall long-term survival was $74 \% \pm 6 \%$ at 5 years and $62 \% \pm 3 \%$ at 10 years (Figure 1 ). Cox regression analysis identified the presence of renal failure (hazard ratio $=2.7,95 \%$ CI $1.3-5.6$ ) and recurrent endocarditis (hazard ratio $=1.9,95 \%$ CI $1.5-3.2$ ) as predictors of late death.

Recurrent endocarditis occurred in 9 patients: 2 during the first postoperative year and 7 in subsequent years. Of the 9 patients with recurrent endocarditis, 5 had involvement of multiple valves and 4 had only single valve involvement. The offending microorganisms were the same as in the first infection in 2 patients, different in 4 , and culture negative in 3 . Five patients underwent reoperation with $2(40 \%)$ deaths, and 4 patients were treated with antibiotics alone with 3 $(75 \%)$ deaths. Freedom from recurrent endocarditis was $86 \% \pm 7 \%$ at 5 years and $74 \% \pm 5 \%$ at 10 years (Figure 2 ). No predictors of recurrent endocarditis could be identified.

There were 8 reoperations: 5 for recurrent endocarditis, 2 for bioprosthetic valve degeneration, and 1 for valve dehiscence. Freedom from reoperation was $88 \% \pm 9 \%$ at 5 years and $73 \% \pm 6 \%$ at 10 years (Figure 3).

Other valve-related complications were primary tissue failure of bioprosthetic valves in 3 ( 2 were reoperated on), valve dehiscence in 2 ( 1 underwent reoperation), and thromboembolic events in 2 .

\section{DISCUSSION}

Infective endocarditis is a clinical challenge that is often associated with a high morbidity and mortality. ${ }^{12}$ Despite appropriate antibiotic use, surgical intervention is required in $20 \%$ to $40 \%$ of cases. ${ }^{3,4}$ Echocardiography demonstrated endocarditis on a single valve in most cases. The involvement of two valves occurs much less frequently, and triple or quadruple valve involvement is extremely uncommon. ${ }^{13}$ MVE is a separate clinical entity, which was recognized to be an independent risk factor affecting survival in patients with native or prosthetic endocarditis. ${ }^{14}$ The incidence of MVE was $18 \%$ in the series reported by Kim and colleagues ${ }^{13}$ and $31 \%$ in that of David and colleagues. ${ }^{15}$ In 
TABLE 3. Diagnosis of MVE by preoperative TTE, TEE, and intraoperative finding

\begin{tabular}{|c|c|c|c|c|c|c|c|}
\hline \multirow[b]{2}{*}{ Valves involved } & \multicolumn{3}{|c|}{ TTE $(n=48)$} & \multicolumn{3}{|c|}{ TEE $(\mathbf{n}=22)$} & \multirow{2}{*}{$\begin{array}{l}\begin{array}{l}\text { Intraoperative findings } \\
(\mathrm{n}=48)\end{array} \\
\mathrm{MVE} \\
\end{array}$} \\
\hline & MVE & SVE & Normal & MVE & SVE & Normal & \\
\hline $\mathrm{MV}$ and $\mathrm{AV}$ & 21 & 9 & 10 & 13 & 4 & 1 & 40 \\
\hline $\mathrm{AV}$ and $\mathrm{TV}$ & 0 & 1 & 0 & 1 & 0 & 0 & 1 \\
\hline $\mathrm{AV}$ and $\mathrm{PV}$ & 0 & 2 & 0 & 1 & 0 & 0 & 2 \\
\hline $\mathrm{PV}$ and $\mathrm{TV}$ & 0 & 2 & 0 & 0 & 0 & 0 & 2 \\
\hline $\mathrm{MV}, \mathrm{AV}$ and $\mathrm{PV}$ & 1 & 0 & 0 & 0 & 0 & 0 & 1 \\
\hline $\mathrm{MV}, \mathrm{AV}, \mathrm{PV}$ and TV & 2 & 0 & 0 & 2 & 0 & 0 & 2 \\
\hline Total No. $(\%)$ & $24(50.0)$ & $14(29.2)$ & $10(20.8)$ & $17(77.3)$ & $4(18.2)$ & $1(4.5)$ & $48(100)$ \\
\hline
\end{tabular}

Data presented are number of patients (percentages in parentheses). MVE, Multivalvular endocarditis; TTE, transthoracic echocardiography; TEE, transesophageal echocardiography; $S V E$, single valve endocarditis; $M V$, mitral valve; $A V$, aortic valve; $T V$, tricuspid valve; $P V$, pulmonary valve.

our series, among 388 patients with documented infective endocarditis reviewed, we found $48(12.4 \%)$ patients who had MVE. Streptococcus viridans was the most frequent cause of native MVE in our patient population, which was consistent with the report by Mihaljevic and colleagues ${ }^{16}$ but was different from the report by Kim and colleagues, ${ }^{13}$

TABLE 4. Operative data

\begin{tabular}{|c|c|}
\hline \multicolumn{2}{|l|}{ Operative procedures } \\
\hline AVR and MVR & 25 \\
\hline AVR and MVP & 8 \\
\hline AVR and PVP & 1 \\
\hline AVP and TVP & 1 \\
\hline AVP and TVR & 1 \\
\hline PVR and TVP & 1 \\
\hline PVP and TVP & 1 \\
\hline AVR and MVR with reconstruction of mitral annulus & 4 \\
\hline $\begin{array}{l}\text { Bentall and MVR with reconstruction of the } \\
\text { intervalvular fibrous body procedure }\end{array}$ & 2 \\
\hline $\begin{array}{l}\text { AVR and MVR with reconstruction of the } \\
\text { intervalvular fibrous body procedure }\end{array}$ & 1 \\
\hline AVR, MVR, and PVP & 1 \\
\hline AVR, MVR, PVP, and TVP & 1 \\
\hline AVR, MVR, PVR, and TVR & 1 \\
\hline \multicolumn{2}{|l|}{ Additional procedures } \\
\hline Repair of congenital VSD & 5 \\
\hline Repair of congenital VSD and Valsalva aneurysm & 2 \\
\hline Repair of congenital ASD & 1 \\
\hline Repair of TOF & 1 \\
\hline Repair of PDA & 2 \\
\hline Repair of DCRV + PS & 1 \\
\hline CABG & 2 \\
\hline Aortic clamping time (mean $\pm \mathrm{SD}$, min) & $58 \pm 28$ \\
\hline Cardiopulmonary bypass time (mean $\pm \mathrm{SD}$, min) & $113 \pm 29$ \\
\hline Days in ICU (mean $\pm \mathrm{SD})$ & $7.4 \pm 3.7$ \\
\hline Days in hospital (mean $\pm \mathrm{SD})$ & $19.5 \pm 8.3$ \\
\hline \multicolumn{2}{|c|}{$\begin{array}{l}A V R \text {, Aortic valve replacement; } M V R \text {, mitral valve replacement; } M V P, \text { mitral valvulo- } \\
\text { plasty; } P V P, \text { pulmonary valvuloplasty; } A V P \text {, aortic valvuloplasty; } T V P \text {, tricuspid val- } \\
\text { vuloplasty; } T V R \text {, tricuspid valve replacement; } P V R \text {, pulmonary valve replacement; } \\
V S D \text {, ventricular septal defect; } A S D \text {, atrial septal defect; } T O F \text {, tetralogy of Fallot; } \\
P D A \text {, patent ductus arteriosus; } D C R V+P S \text {, double-chambered right ventricle and pul- } \\
\text { monary valve stenosis; } C A B G \text {, coronary artery bypass grafting; } S D \text {, standard devia- } \\
\text { tion; } I C U \text {, intensive care unit. }\end{array}$} \\
\hline
\end{tabular}

in which the most common etiologic microorganism was Staphyloccocus aureus.

The majority of patients with MVE had aortic and mitral valve involvement, whereas triple or quadruple valve involvement was rare. In patients with involvement of the aortic and mitral valves, aortic valve endocarditis is generally thought to be the primary event. The most common pathologic finding is aortic valve endocarditis with an associated lesion on the anterior leaflet of the mitral valve. The lesion may be a vegetation, aneurysm, or frank perforation. The pathogenesis of the mitral valve lesion is thought to involve a jet of aortic regurgitation that produces an infected lesion on the anterior mitral leaflet. Other less common mechanisms of anterior leaflet mitral valve involvement in patients with aortic valve endocarditis include repeated impingement of a prolapsing aortic vegetation on the anterior mitral leaflet and direct extension of the infectious abscess along the mitral-aortic intervalvular fibrous body. ${ }^{5}$ In the series reported by Kim and colleagues, ${ }^{13}$ all 14 cases involved two valves and there were no cases of triple or quadruple valve endocarditis. In our series, 1 patient had triple valve endocarditis and 2 had quadruple valve endocarditis. MVE with biventricular involvement is uncommon and is mainly described in patients with prolonged intravenous infusions, in patients addicted to intravenous drugs, or in patients with CHD and a shunt. ${ }^{17}$ In our series, 6 patients had biventricular involvement. All of them had predisposing CHD and

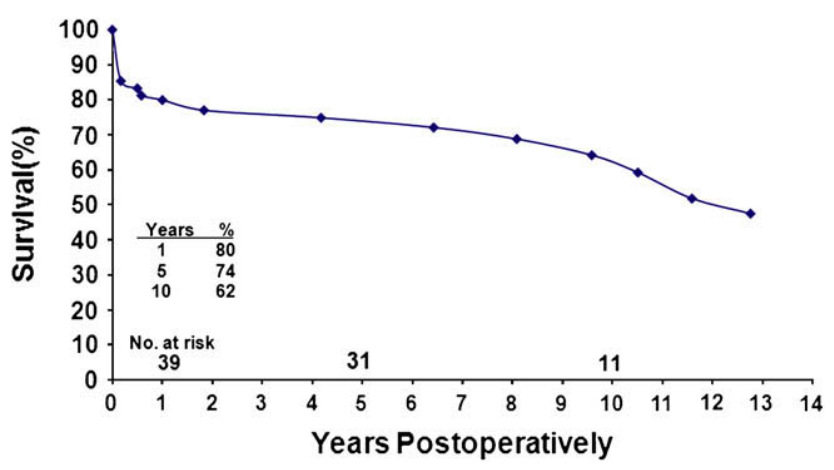

FIGURE 1. Long-term survival after valve surgery. 


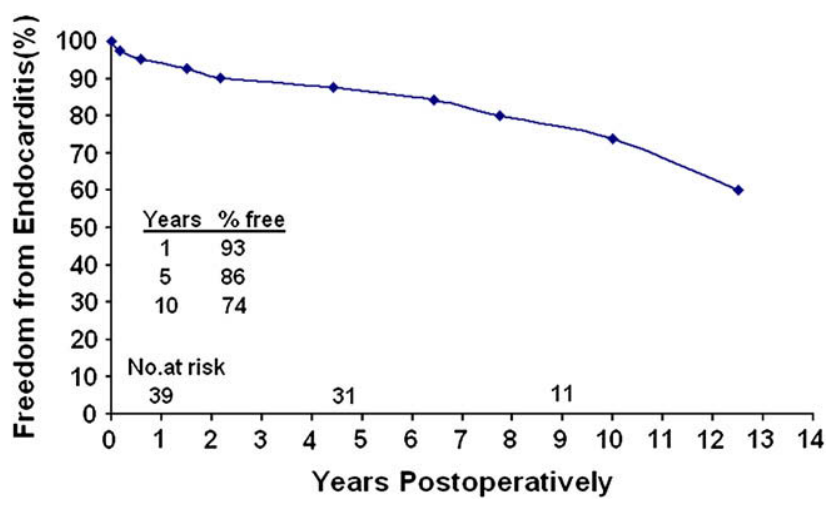

FIGURE 2. Long-term freedom from endocarditis.

none was addicted to intravenous drugs. In Mainland China, persons with CHD are apt to receive their diagnosis at a later age than those in developed countries. Inasmuch as many people live in rural areas where poverty and lack of health care is prevalent, it is not until endocarditis or other severe complications develop that CHD is diagnosed. Biventricular involvement of multiple valves in these patients can be attributed to left-to-right ventricular communication. The infection on one side of the heart could easily spread through the left-to-right shunt produced by the $\mathrm{CHD}$, thus affecting valves on both sides of the heart. ${ }^{7}$

Demonstration of multivalvular involvement in patients with suspected infective endocarditis is extremely important. A finding of multiple valve lesions by any means enables the identification of patients who are at higher risk of complications, which, in turn, increases the ability to optimally manage the patients. In these patients, any omission will result in disastrous outcomes. In our opinion, two basic principles are important for the successful demonstration of MVE. First, the use of TEE is extremely helpful for demonstration of multivalvular involvement before surgery when the TTE images are not optimal. The use of TEE increases sensitivity and specificity to about $90 \% .{ }^{18}$ Second, careful intraoperative exploration plays a significant role in confirming the diagnosis of MVE, especially in patients with risk factors such as severe aortic root abscess, predisposing CHD with shunt, intravenous drug use, and so on. MVE was diagnosed preoperatively by TTE in only $50.0 \%$ of patients in our series and by preoperative TEE in $77.3 \%$. Fortunately, MVE was confirmed through surgical exploration in all patients.

Although the need for operative repair in patients with infective endocarditis is clear, the choice of valvular procedure remains controversial. ${ }^{5}$ For patients with mitral valve endocarditis, valvular replacement was proposed in the mid-1960s, whereas more recently mitral valve repair has become popular. In the meta-analysis by Feringa and coworkers, ${ }^{19}$ mitral valve repair was associated with lower in-hospital and long-term mortality, less repeat mitral valve surgery during the early postoperative period and during long-term follow-up, and fewer recurrent endocarditis and

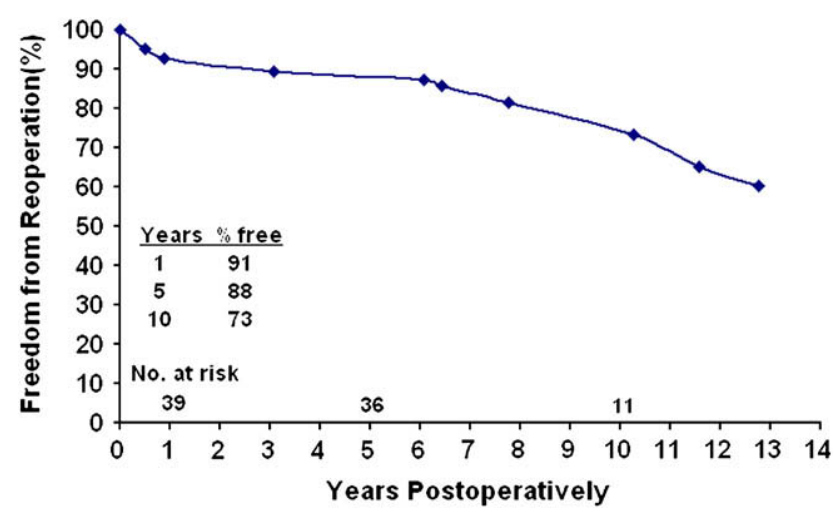

FIGURE 3. Long-term freedom from reoperation.

cerebrovascular events during long-term follow-up as compared with patients who underwent mitral valve replacement. Therefore, when feasible, mitral valve repair is preferred for the surgical treatment of infective endocarditis affecting the mitral valve. For aortic valve endocarditis, Aranki and coworkers ${ }^{20}$ reported excellent results using standard prosthesis replacement. However, allograft aortic valve replacement has distinct advantages, especially when the aortic root is also involved. The homografts mold well to the fragile infected aortic annulus, have good resistance to infection, have excellent hemodynamic performance especially in small sizes, and do not require anticoagulation. ${ }^{21}$

The hospital mortality of $12.5 \%$ in this series compares favorably with that in Kim's series ${ }^{13}$ and Mihaljevic's series, ${ }^{16}$ which reported operative mortalities of $21 \%$ and $16 \%$, respectively. In our series, patients with prosthetic valve endocarditis were not included and $33.3 \%$ of our patients had had a previous episode of remote endocarditis. This patient mix may be the main reason for the low hospital mortality in this complex category of patients. Mihaljevic and colleagues ${ }^{16}$ found that the presence of an abscess at the time of the operation was the only significant variable influencing hospital mortality. In our series, however, the presence of preoperative renal failure was found to be the most important risk factor, with an odds ratio of 5.9, and New York Heart Association class IV and emergency surgery were also identified as independent predictors for hospital mortality. The overall survivals in our series at 5 and 10 years were $74 \%$ and $62 \%$, respectively, which were not substantially different from those reported by Mihaljevic and colleagues ${ }^{16}$ of $87 \%$ and $64 \%$ at 5 and 10 years, respectively.

Operative mortality in patients with NVE ranges from $0 \%$ to $10 \%$. Late survival in these patients is good, with 5 -year survival of approximately $80 \%$ and 10 -year survival of approximately $60 \%$. Ten-year freedom from recurrent endocarditis after operation for NVE is approximately $80 \%{ }^{5}$ We present the largest series of these procedures from China. In our study, hospital mortality was $12.5 \%$, which is similar to that for single valve endocarditis. Ten-year survival was $73 \%$ and 10 -year freedom from recurrent 
endocarditis was $74 \%$, which are also similar to those reported for single valve endocarditis. However, our results could have been worse if we had had more patients with acute endocarditis based on the fact that surgical treatment and outcomes of patients with endocarditis are vastly different depending on the acuity of their disease.

Several limitations are inherent to the present study. First, this is a retrospective single-institution study. Second, this is a clinical study of a relatively small number of patients. Another limitation is the long time period of the analysis; changes in diagnostic criteria for NVE and surgical technique may influence outcome and prognostic factors. We have started a prospective study of MVE at our institution since 2007, and we will probably provide more convincing conclusions in a few years.

In conclusion, MVE was diagnosed by TTE in only half of affected patients at our institution. Intraoperative TEE provided a more effective means to identify MVE. Radical resection of all infected tissues for patients with MVE and additional intraoperative interventions depending on the operative pathologic status produced satisfactory in-hospital and long-term results, similar to those in patients with a single infected heart valve.

\section{References}

1. Moreillon P, Que YA. Infective endocarditis. Lancet. 2004;363:139-49.

2. Weinstein MP, Stratton CW, Ackley A, Hawley HB, Robinson PA, Fisher BD, et al. Multicenter collaborative evaluation of a standardized serum bactericidal test as a prognostic indicator in infective endocarditis. Am J Med. 1985;78: 262-9.

3. Vlessis AA, Havaguimian H, Jaggers J, Ahmad A, Starr A. Infective endocarditis: ten-year review of medical and surgical therapy. Ann Thorac Surg. 1966;61: 1217-22.

4. Jassal DS, Neilan TG, Pradhan AD, Lynch KE, Vlahakes G, Agnihotri AK, et al. Surgical management of infective endocarditis: early predictors of short-term morbidity and mortality. Ann Thorac Surg. 2006;82:524-9.
5. Gillinov AM, Diaz R, Blackstone EH, Pettersson GB, Sabik JF, Lytle BW, et al. Double valve endocarditis. Ann Thorac Surg. 2001;71:1874-9.

6. Krake PR, Zaman F, Tandon N. Native quadruple-valve endocarditis caused by Enterococcus faecalis. Tex Heart Inst J. 2004;31:90-2.

7. Bavunoglu I, Sahin S, Yilmaz M, Toptas T, Tabak F, Tunckale A. Native triplevalve endocarditis caused by penicillin-resistant Streptococcus sanguis. Nature Clin Pract Cardiovasc Med. 2007;4:340-3.

8. Deonarine B, Lazar J, Gill MV, Cunha BA. Quadri-valvular endocarditis caused by Streptococcus mutans. Clin Microbiol Infect. 1997;3:139-41.

9. Henderson RA, Palmer TJ. Echocardiographic diagnosis of infective endocarditis of all four cardiac valves. Int J Cardiol. 1991;33:173-5.

10. Durack DT, Lukes AS, Bright DK, and the Duke Endocarditis Service. New criteria for diagnosis of infective endocarditis: utilization of specific echocardiographic findings. Am J Med. 1994;96:200-9.

11. Akins CW, Miller DC, Turina MI, Kouchoukos NT, Blackstone EH, Grunkemeier GL, et al. Guidelines for reporting mortality and morbidity after cardiac valve interventions. J Thorac Cardiovasc Surg. 2008;135:732-8.

12. Mylonakis E, Calderwold SB. Infective endocarditis in adults. $N$ Engl J Med. 2001;345:318-30.

13. Kim N, Lazar JM, Cunha BA, Liao W, Minnaganti V. Multi-valvular endocarditis. Clin Microbiol Infect. 2000;6:207-12.

14. Grover FL, Cohen DJ, Oprian C, Henderson WG, Sethi G, Hammermeister KE. Determinants of the occurrence of and survival from prosthetic valve endocarditis. J Thorac Cardiovasc Surg. 1994;108:207-14.

15. David TE, Gavra G, Feindel CM, Regesta T, Armstrong S, Maganti MD. Surgical treatment of active infective endocarditis: a continued challenge. J Thorac Cardiovasc Surg. 2007;133:144-9.

16. Mihaljevic T, Byrne JG, Cohn LH, Serraf A, Gruber P, Macé L, et al. Long-term results of multivalve surgery for infective endocarditis. Eur J Cardiothorac Surg. 2001;20:824-6.

17. Allocca G, Slavich G, Nucifora G, Slavich M, Frassani R, Crapis M, et al. Successful treatment of polymicrobial multivalve infective endocarditis. Int J Cardiovasc Imaging. 2007;23:501-5.

18. Flachskampf F, Daniel WG. Role of transesophageal echocardiography in infective endocarditis. Heart. 2000;84:3-4.

19. Feringa HH, Shaw LJ, Poldermans D, Hoeks S, van der Wall EE, Dion RA, et al. Mitral valve repair and replacement in endocarditis: a systematic review of literature. Ann Thorac Surg. 2007;83:564-71.

20. Aranki SF, Santini F, Adams DH, Rizzo RJ, Couper GS, Kinchla NM, et al. Aortic valve endocarditis: determinants of early survival and late morbidity. Circulation. 1994;90(Pt 2):II175-82.

21. Niwaya K, Knott-Craig CJ, Santangelo K, Lane MM, Chandrasekaran K, Elkins RC. Advantage of autograft and homograft valve replacement for complex aortic valve endocarditis. Ann Thorac Surg. 1999;67:1603-8. 